\title{
EXPERIMENTAL STUDY OF CARRIAGEWAY OPERATIONAL CONDITION INFLUENCE ON ACOUSTIC ROADSIDE AREA POLLUTION
}

\author{
Evgenija UGNENKO ${ }^{1}$, Vadim GAVRISH ${ }^{2}$, Gintas VISELGA ${ }^{3}$, \\ Giedrius GARBINČIUS ${ }^{4}$, Vytautas TURLA ${ }^{5}$, Saulius NAGURNAS ${ }^{6}$ \\ ${ }^{1}$ Dept of Surveys and Designing of Communication, Geodesy and Land Management; \\ Ukrainian State University of Railway Transport, Kharkiv, Ukraine \\ ${ }^{2}$ Dept of Land Management and Cadastre, Lugansk National Agrarian University, Kharkiv, Ukraine \\ ${ }^{3}$ Dept of Mechanics and Materials Engineering, Vilnius Gediminas Technical University, Vilnius, Lithuania \\ ${ }^{4}$ Dept of Mechatronics, Robotics and Digital Manufacturing, \\ Vilnius Gediminas Technical University, Vilnius, Lithuania \\ 5, 6 Dept of Automobile Engineering, Vilnius Gediminas Technical University, Vilnius, Lithuania
}

Received 30 December 2016; revised 31 March 2018, 27 July 2018; accepted 13 September 2018

\begin{abstract}
Environmental noise management is an important part of the policy across the EU policy context, because transportation noise is a significant local environmental problem for most of the urban population. Increasing numbers of vehicles are associated with growing noise levels from road transport in urban areas and rising public health problems. Motor transport is considered to be a main source of noise pollution, so it is important to investigate the level of traffic noise and assess the relationship with traffic flows. The paper describes the main methods for determination of noise characteristics of traffic flows. The dependences for the prediction of the equivalent noise level and the results of field measurements of sound levels are presented. The results of field experiments and the calculated values of sound levels obtained by the analytical method are tested for homogeneity, using the Wilcoxon test. Experimental studies have established that the external sound level depends largely on the speed of vehicles, road conditions, and basic operating characteristics of highways. The analytical method associated with the use of deterministic and probabilistic models makes it possible to predict the traffic noise. But when dealing with the foregoing methods, there arise specific problems, many of which have not been resolved: there is no uniform terminology, nor is there any consensus on the use of noise characteristics of traffic flows in calculations at different stages of construction and reconstruction of highways of a certain traffic flow model under conditions of human settlements. Standardized measurement methods have been established and revised throughout the years by many renowned researchers. These methodologies have been revised in order to minimize problems that may occur and may not be foreseen by a less experienced researcher when adopting the measurement methods. Standardizing the measurement method is also useful for researchers because it becomes possible for researchers from around the world to compare their data. The joint effect of road conditions and the operational status of the roadway on the acoustic pollution of the roadside area is not fully taken into account. Therefore, applying the internationally recognized acoustical measurement standards is a good way to start any noise measurement experiment. The purpose of experimental research is to investigate the joint effect of road conditions and the operational status of the roadway on the acoustic pollution of the roadside area of settlements: identify the main characteristics of noise produced by traffic flows, consider the comparability of results of the field experiment and analytical computations. Slopes of $20 . . .40 \%$ have little impact on the noise caused by the movement of passenger cars and trucks. In this case, the average acoustic emissions are identical to those used in the prediction of noise mode.
\end{abstract}

Keywords: noise, acoustic emission, equivalent noise level, road, traffic, roadside area.

\section{Introduction}

As technology advances, more roads are built and more vehicles made to meet the demand and desire of humans to reach every part of the world with ease. Traffic volumes are ever increasing, and hence traffic noise pollution is be- coming one of the most critical issues in society (Ugnenko et al. 2017). According to a EU publication (WHO 2018):

- about $40 \%$ of the population in EU countries is exposed to road traffic noise at levels exceeding $55 \mathrm{~dB}(\mathrm{~A})$;

${ }^{*}$ Corresponding author. E-mail: gintas.viselga@vgtu.lt 
- $20 \%$ is exposed to levels exceeding $65 \mathrm{~dB}(\mathrm{~A})$ during the daytime;

- more than $30 \%$ is exposed to levels exceeding $55 \mathrm{~dB}(\mathrm{~A})$ at night.

The World Health Organization guidelines for community noise recommend less than $30 \mathrm{~dB}(\mathrm{~A})$ in bedrooms during the night for a sleep of good quality and less than $35 \mathrm{~dB}(\mathrm{~A})$ in classrooms to allow good teaching and learning conditions. In the night noise recommend less than $40 \mathrm{~dB}(\mathrm{~A})$ of annual average outside of bedrooms to prevent adverse health effects from night noise (WHO 2018). According to the existing laws, noise levels in residential areas during the day cannot exceed $65 \mathrm{~dB}(\mathrm{~A})$ (Bikuviene, Juodkiené 2017).

Environmental noise management is an important part of the policy across the EU policy context, because transportation noise is a significant local environmental problem for most of the urban population. Increasing numbers of vehicles are associated with growing noise levels from road transport in urban areas and rising public health problems. Motor transport is considered to be a main source of noise pollution, so it is important to investigate the level of traffic noise and assess the relationship with traffic flows (Miškinyte, Dèdele 2014). Road traffic is the most dominant source of environmental noise, with an estimated 125 million people affected by noise levels greater than $55 \mathrm{~dB}$ (day-evening-night level) (EEA 2014). Road transport is one of the most important environmental polluters in Europe as well as in Lithuania, Ukraine, and other countries, though more attention is paid to air quality problems than to noise pollution (Smolnikovas et al. 2015). The transport systems in these countries are dominated by relatively old vehicles that are prone to generate high levels of traffic noise. The lack of economic means has made the process of upgrading transportation vehicles to more modern and less noisy models in Lithuania much slower than in other EU countries (Ilgakojis et al. 2005). The engine noise and the interaction between vehicle tyres and the road surface are two major sources of road transport noise (Miškinyté, Dèdelè 2014). Both the tyre and the road surface play an important role in the tyre/road noise generation which involves structural vibration and aerodynamic mechanisms. The interaction between the rolling tyre and road surface produces noise and vibration that can be amplified by different mechanisms like resonance and horn effects (Sandberg, Ejsmont 2002). Tyre cavity resonance is an important interior noise in the range of $200 \ldots 300 \mathrm{~Hz}$ (Tanaka et al. 2016; Mohamed, Wang 2016). Also, vehicle speed, road surface material and its porosity, as well as tyre structure and tread pattern are factors influencing the tyre/road noise level (Sandberg, Glaeser 2008). Vehicle exterior and interior noise are produced from sound radiating from the vibrating tyre structure and from air pushed between the tread blocks and the road surface (Tanaka et al. 2016).

Traffic noise has large consequences on the appreciation of the living quality close to roads and leads to speech interference, sleep disturbances, and general annoyance.
Furthermore, it impacts the economy as it increases the costs for noise abatement and decreases the value of properties, which are close to noisy road transport infrastructure (Masino et al. 2017). Traffic noise control technology is gaining more attention from society nowadays, and many traffic noise control measures have been implemented (Ho et al. 2013). Vehicle noise regulation is important, especially in light of growing traffic volumes and the proximity between transport infrastructure and residential and living areas. Every doubling of transport intensity increases noise levels by $3 \mathrm{~dB}(\mathrm{~A})$. Vehicle noise regulation goes back to the 1970s, with tyre/road noise regulation added in 2001 and thereafter. In their present form, however, both sets of legislation are too liberal to have had any significant effect, and the number of people exposed to ambient noise has consequently increased rather than declined (Den Boer, Schroten 2007). As one of the most popular methods to reduce road traffic noise, noise barriers are installed along the road, but the excessive cost of installation and maintenance has been identified as the problem, and rising height has increasingly been a blot on the landscape (Moon et al. 2013). In Japan, active noise control technology was applied to noise barriers in 2004. Active noise reduction technology is intended to reduce the noise by generating counter-noise with the same level and frequency after converting $180^{\circ}$ the frequency of the noise (Moon et al. 2013).

Noise can disturb people's daily life and affect people's work performance. And long-term excess noise exposure can lead to hearing damage and even psychological disorder (Ho et al. 2013). Noise impact and noise reduction policies could produce significant effects on the economies of EU countries, in which health-related costs alone account for $0.2 \ldots 2.0 \%$ of the annual Gross National Product (Morgan 2006).

The materials and techniques used in the construction of any particular road pavement surface are significant contributors to the levels of road traffic noise that are generated by that pavement surface. Moreover, the noise outputs generated from certain types of pavements have been found to be more annoying than those generated on other types of pavements, even when the overall noise levels generated on each pavement are similar. Basic noise characteristics of traffic flows depend on (1) intensity, velocity, and specific gravity of trucks in the traffic flow; (2) traffic management; (3) traffic conditions; (4) the operational condition of the roadway (Parnell, Samuels 2006; Samuels, Parnell 2001). Therefore, it is important to have standard guidelines for collecting acoustical measurements and interpreting the results accurately (ISO 118191:1997; ISO 11819-2:2017; GOST 31330.1:2006).

Many guidelines and recommendations are available for measuring the acoustical properties and interpreting the results. Currently, computational methods have been developed that make it possible to establish certain noise characteristics under traffic conditions in communities, namely, the methods of field measurements, analytical methods, and modelling techniques. The method 
of field measurements allows investigation of the effect of the above parameters in a real traffic flow, to establish sanitary and hygienic assessment of noise within an appropriate time period. The method of field measurements that makes it possible to determine the noise characteristics of transport flows, as well as sound levels produced by the traffic in residential areas, in resident and public buildings is introduced into a number of standards. The analytical method associated with the use of deterministic and probabilistic models makes it possible to predict the traffic noise.

However, the foregoing methods are associated with specific problems, many of which have not been resolved: there is no uniform terminology; nor is there any consensus regarding the use of noise characteristics of traffic flows in calculations at different stages of construction and reconstruction of highways of a certain traffic flow model under conditions of human settlements. Standardized measurement methods have been established and revised throughout the years by many renowned researchers. These methodologies have been revised in order to minimize problems that may occur and may not be foreseen by a less experienced researcher when adopting the measurement methods. Standardizing the measurement method is also useful for researchers because it becomes possible for researchers from around the world to compare their data. The joint effect of road conditions and the operational status of the roadway on the acoustic pollution of the roadside area is not fully taken into account. Therefore, applying the internationally recognized acoustical measurement standards is a good way to start any noise measurement experiment.

In the literature, a large number of noise forecasting models, referring to different types of roads (urban roads, motorways, and so on), is reported. Such models generally consist of empirical equations that allow calculations of noise levels associated with traffic flow showing determined composition (heavy vehicles, motorcycles, cars) and characteristics (velocity, flux, etc.) (Nucara et al. 2001).

The purpose of the experimental study is to investigate the joint effect of road conditions and the operational status of the roadway on the acoustic pollution of the roadside area of settlements: identify the main characteristics of noise produced by traffic flows and consider the comparability of the results of the field experiment and analytical computations.

\section{Theoretical study}

Numerous field measurements conducted in various localities of the Kharkiv region revealed a correlation for the background level $L_{f}$ during peak hours (Ugnenko 2008):

$$
L_{f}=10 \cdot \lg Q-6-\Delta L_{f},
$$

where: $Q$ is population of people; $\Delta L_{f}=0 \mathrm{~dB}(\mathrm{~A})$ for small and medium-sized towns, $\Delta L_{f}=10 \mathrm{~dB}(\mathrm{~A})$ for peripheral areas.
With the introduction of state standards for allowable exterior noise of vehicles, industries in Europe have begun to produce cars with a regulated noise characteristic of each kind. The following are the maximum permissible sound levels $\mathrm{dB}(\mathrm{A})$ at a distance of $7.5 \mathrm{~m}$ from the axis of movement at a speed of $50 \mathrm{~km} / \mathrm{h}$ (Table 1).

Table 1. Maximum permissible sound levels $\mathrm{dB}(\mathrm{A})$ at a distance of $7.5 \mathrm{~m}$ from the axis of movement at a speed of $50 \mathrm{~km} / \mathrm{h}$

\begin{tabular}{|c|c|}
\hline Vehicle & $\begin{array}{c}\text { Maximum } \\
\text { permissible sound } \\
\text { level } \mathrm{dB}(\mathrm{A})\end{array}$ \\
\hline \multicolumn{2}{|c|}{$\begin{array}{l}\text { Trucks and utility vehicles with the wheel formula }(4 \times 4) \text {, } \\
\text { tractor trucks, vans with full weight [t] }\end{array}$} \\
\hline$<3.5 \mathrm{t}$ & 84 \\
\hline $3.5 \ldots 12.0 \mathrm{t}$ & 89 \\
\hline \multicolumn{2}{|c|}{$>12000 \mathrm{~kg}$ with the engine capacity [kW]: } \\
\hline$<162 \mathrm{~kW}$ & 89 \\
\hline$>162 \mathrm{~kW}$ & 91 \\
\hline \multicolumn{2}{|c|}{ Buses with a total weight $[\mathrm{t}]$} \\
\hline$<3.5 \mathrm{t}$ & 84 \\
\hline \multicolumn{2}{|c|}{$>3.5 \mathrm{t}$ with the engine capacity $[\mathrm{kW}]:$} \\
\hline$<162 \mathrm{~kW}$ & 89 \\
\hline$>162 \mathrm{~kW}$ & 91 \\
\hline \multicolumn{2}{|c|}{$\begin{array}{l}\text { Motorcycles, scooters, mopeds, and motorbikes } \\
\text { with engine capacity }\left[\mathrm{cm}^{3}\right]\end{array}$} \\
\hline$<50 \mathrm{~cm}^{3}$ & 80 \\
\hline $50 \ldots 125$ & 82 \\
\hline $125 \ldots 500 \mathrm{~cm}^{3}$ & 84 \\
\hline$>500 \mathrm{~cm}^{3}$ & 86 \\
\hline
\end{tabular}

Increased roughness of the road surface $\Delta L_{\lambda_{M}}$ increases the sound level of a single vehicle (Ugnenko 2008):

$$
\Delta L_{\lambda_{M}}=3 \cdot \lg \frac{\lambda_{M}}{0.3}
$$

where: $\lambda_{M}$ is the macroroughness within the range of $0.3 \ldots 10.0 \mathrm{~mm}$.

On the basis of the foregoing, one can set the projected equivalent noise level $L_{A \text { equiv }}$ at reference points of the roadside area of a locality by the formula (Ugnenko 2008):

$$
\begin{aligned}
& L_{\text {A equiv }}=10 \cdot \lg \left(\frac{Q}{4 \cdot 10^{0.1 \cdot \Delta L_{f}}}+1.2 \cdot 10^{-9} \cdot N \cdot \xi_{m} \times\right. \\
& \left.V^{2.4} \cdot \lambda_{M}^{0.3} \cdot\left(\sum_{i=1}^{f_{n}} \rho_{i} \cdot 10^{0.1} \cdot L_{50 i}\right) \cdot \sum_{i=1}^{m} \frac{1}{d_{i}}\right)
\end{aligned}
$$

where: $N$ is the intensity of one traffic lane [veh/h]; $V$ is the average speed on a given road section $[\mathrm{km} / \mathrm{h}] ; f_{n}$ is the number of accounted types of vehicles in the transport stream; $\rho_{i}$ is the percentage of the $i$-type of vehicle in the traffic flow [\%]; $L_{50 i}$ is the known sound level of the $i$-type of vehicle at a distance of $7.5 \mathrm{~m}$ from the axis of movement at a speed of $50 \mathrm{~km} / \mathrm{h}[\mathrm{dB}(\mathrm{A})] ; d_{i}$ is the distance from the point of calculation to the traffic lane axis [m]; $m$ is the sequence number; $\xi_{m}$ is the coefficient that al- 
lows the road conditions and the operational status of the roadway to be taken into account.

To determine the analytical dependence of the hourly equivalent sound level as a function of parameters characterizing the traffic flow, the state of coating, and the background noise, a number of idealizations have been introduced. As a result, the formula previously referred to was tested by comparing the results obtained with field measurements and calculated values by other methods. Data (Table 2) yielded by the experimental studies were accepted as the calculated values.

\section{Research methodology}

Experimental studies are classified as passive because they do not make it possible to vary the factors that determine the setting of acoustic pollution levels of the roadside area. Particular attention was paid to the choice of experimental road sections. The studies were conducted on the road sections of highways Kyiv-Kharkiv, Kyiv-Lviv-Cracow.

The Statistical Pass-By (SPB) method is described in the ISO 11819-1:1997 standard. It provides a method to determine an index which can be used to compare the noise emission impact of different road surfaces by measuring vehicle passbys at the roadside. This can either be a tool for classifying and ranking different types of road surfaces according to their influence on noise emission or for evaluating the effect of different road surfaces at a particular site, especially before and after resurfacing. Method is based on the measurement of the maximum A-weighting sound pressure levels of a statistically significant number of individual vehicle passbys together with the vehicle speeds. The passing vehicles are classified into one of three vehicle categories and one of three reference speeds is chosen according to the average operating speed of the road. The vehicle speed was measured when passing the microphone with an accuracy of $\pm 3 \%$.

The main reasons for the limited applicability of the SPB method are the very strict requirements. Those concern the test sites, the traffic and the road surface itself and the weather conditions. The road surface shall be: in good condition, homogeneous, dry and, if possible, the whole distance between the lane and the microphone should be covered with the same road surface. The selected test section should provide essentially free-field conditions for sound measurements. It should fulfil the following list of criteria:
- the minimum length of the test section should be $60 \mathrm{~m}$ (100 $\mathrm{m}$ for high-speed roads);

- no bends or gradients $>1 \%$;

- no large reflecting surfaces shall be present;

- no screening objects shall be present within the area between the microphone and the road;

- A-weighting sound pressure levels from other sources than traffic shall be at least $10 \mathrm{~dB}$ below the quietest maximum sound levels recorded during the passbys.

Field measurements of the equivalent level of traffic noise were conducted according to current Ukraine practices during the daytime and at peak times in the summer by the precision Integrating Sound Level Meter Type 0026 (RFT Company, Germany). The sound level instrumentation shall be checked once every year for compliance with the aforementioned standards. In addition to that, the sensitivity of the whole acoustic measurement setup must be checked with an acoustic calibrator before and after the measurements. The calibrator must meet the requirements (Class 0 or 1) of IEC 60942:2017. If the readings differ more than $0.5 \mathrm{~dB}$, the measurement is invalid. The microphone was located $2 \mathrm{~m}$ from the outer fence of the building at a height of $1.5 \mathrm{~m}$ from the ground level during the time interval when cars were moving at a steady speed basically in the middle of the roadway. The duration of continuous measurements of noise levels was accepted depending on the intensity of the traffic flow. For traffic flows with an intensity of more than $1000 \mathrm{veh} / \mathrm{h}$, the duration of measurements constituted $15 \mathrm{~min}$, and for those with an intensity of $500 \ldots 1000 \mathrm{veh} / \mathrm{h}$, the duration of measurements -20 min.

The measurement of air temperature is mandatory, whereas the measurement of surface temperature is optional. The instrument shall have a maximum error of $1{ }^{\circ} \mathrm{C}$. Wind speeds must not exceeding $5 \mathrm{~m} / \mathrm{s}$ during the measurement. For the vehicle speed and temperature measurement equipment, no special calibration procedures are required in the standard apart from the error limits.

\section{Course, results of tests, and discussion}

The experimental design included a selection of samples of 15 measurements of transport flow noise characteristics. The results of the comparisons of measured and calculated values of noise characteristics of transport flows are shown in Table 3.

Table 2. Estimated values of the sound level of a vehicle

\begin{tabular}{|c|c|c|c|c|c|c|}
\hline \multirow{3}{*}{ Indicators } & \multicolumn{6}{|c|}{ Vehicles } \\
\hline & \multirow{2}{*}{ Cars } & \multicolumn{4}{|c|}{ Trucks with a full weight [t] } & \multirow{2}{*}{ Buses } \\
\hline & & $<2$ & $2 \ldots 5$ & $5 \ldots 8$ & $>8$ & \\
\hline Average weighted sound level $L_{50 \text { iaw }}[\mathrm{dB}(\mathrm{A})]$ & 74.0 & 75.5 & 82.2 & 87.5 & 89.0 & 85.0 \\
\hline Mean-square deviation $\delta[\mathrm{dB}(\mathrm{A})]$ & 3.0 & 3.0 & 3.0 & 3.0 & 2.6 & 2.3 \\
\hline Calculated value of sound level $L_{50 i c v}[\mathrm{~dB}(\mathrm{~A})]$ & 75.0 & 76.3 & 83.5 & 88.5 & 89.6 & 85.4 \\
\hline
\end{tabular}


Table 3. Results of field measurements and analysis of calculation formulas

\begin{tabular}{|c|c|c|c|c|c|c|c|c|c|c|c|c|}
\hline \multirow{3}{*}{$\begin{array}{c}\text { Intensity } \\
\text { [veh/h] }\end{array}$} & \multirow{3}{*}{$\begin{array}{l}\text { Speed } \\
{[\mathrm{km} / \mathrm{h}]}\end{array}$} & \multicolumn{6}{|c|}{ Composition of traffic flow according to the types of vehicles $\rho_{i}[\%]$} & \multicolumn{3}{|c|}{ Sound levels $[\mathrm{dB}(\mathrm{A})]$} & \multicolumn{2}{|c|}{ Error $[\mathrm{dB}(\mathrm{A})]$} \\
\hline & & \multirow{2}{*}{ Cars } & \multirow{2}{*}{ Buses } & \multicolumn{4}{|c|}{ Trucks with a full weight [t] } & \multirow{2}{*}{$L_{\text {mes }}$} & \multirow{2}{*}{$L_{s t}$} & \multirow{2}{*}{$L_{d y n}$} & \multirow{2}{*}{$\nabla_{s t}$} & \multirow{2}{*}{$\nabla_{d y n}$} \\
\hline & & & & $<2$ & $2 \ldots 5$ & $5 \ldots 8$ & $>8$ & & & & & \\
\hline 570 & 66.8 & 62.1 & 15.1 & 5.8 & 5.8 & 4.8 & 6.4 & 73.8 & 73.0 & 71.2 & +0.8 & +2.6 \\
\hline 750 & 60.0 & 64.0 & 3.0 & 8.3 & 8.1 & 9.2 & 7.4 & 72.5 & 72.0 & 72.5 & +0.5 & +0.5 \\
\hline 720 & 68.6 & 76.7 & 4.3 & 6.4 & 6.2 & - & 6.4 & 77.7 & 75.4 & 74.6 & +2.3 & +3.1 \\
\hline 1020 & 65.4 & 73.3 & 9.7 & 4.3 & 3.4 & 5.0 & 4.3 & 76.1 & 76.2 & 74.2 & -0.1 & +1.9 \\
\hline 630 & 72.1 & 67.6 & 4.3 & 7.0 & 7.0 & 6.5 & 8.5 & 72.8 & 72.7 & 75.7 & +0.1 & -2.9 \\
\hline 630 & 78.9 & 62.4 & 4.0 & 7.0 & 7.0 & 9.3 & 10.3 & 75.5 & 75.0 & 73.7 & +0.5 & +1.8 \\
\hline 660 & 75.4 & 66.4 & 8.1 & 25.5 & - & - & - & 76.4 & 74.0 & 74.4 & +2.4 & +2.0 \\
\hline 360 & 68.9 & 63.3 & 1.7 & 20.0 & 15.0 & - & - & 68.7 & 70.8 & 70.1 & -2.1 & -1.3 \\
\hline 480 & 65.0 & 67.5 & 12.6 & 5.0 & 4.9 & 5.0 & 5.0 & 72.1 & 71.3 & 73.1 & +0.8 & -1.0 \\
\hline 570 & 62.5 & 62.1 & 9.5 & 14.2 & 14.2 & - & - & 74.6 & 71.9 & 73.3 & +2.7 & +1.3 \\
\hline 600 & 66.1 & 60.0 & 5.2 & 9.0 & 10.8 & 6.0 & 9.0 & 73.5 & 73.5 & 72.3 & 0 & +1.2 \\
\hline 840 & 72.9 & 72.1 & 5.1 & 11.4 & 11.4 & - & - & 74.4 & 75.9 & 73.1 & -1.5 & +1.3 \\
\hline 540 & 72.1 & 78.9 & 15.3 & 3.8 & - & 2.0 & - & 76.0 & 72.0 & 73.1 & +4.0 & +2.9 \\
\hline 660 & 76.4 & 66.4 & 4.6 & 9.7 & 10.7 & - & 8.6 & 74.6 & 74.0 & 73.1 & +0.6 & +1.5 \\
\hline 690 & 71.8 & 67.9 & 4.4 & 9.2 & 9.2 & - & 9.3 & 74.3 & 72.9 & 71.9 & +1.4 & +2.4 \\
\hline
\end{tabular}

Notes: $L_{\text {mes }}$ - measured value of sound level; $L_{s t}$ - calculated static value of sound level; $L_{d y n}$ - calculated dynamic value of sound level; $\nabla_{s t}-$ static error; $\nabla_{d y n}-$ dynamic error

The obtained errors $\nabla_{d y n}$ and $\nabla_{s t}$ defined as differences $L_{c h a n}-L_{d y n}$ and $L_{c h a n}-L_{s t}$ were tested for homogeneity, using the Wilcoxon test at a level of significance of 0.01 . It was established that errors $\nabla_{d y n}$ and $\nabla_{s t}$ for the given volume of sampling are uniform, and their distribution is close to a normal packet (ISO 11819-1:1997; ISO 11819$2: 2017)$. Thus, the estimated mathematical relation represented by Equation (3) is in good agreement with both the results of field observations and the results of calculations according to the statistical model.

At a large distance from the source of noise, the sound pressure level depends not only on the geometrical parameters, but also on the characteristics of noise propagation in the atmosphere near the ground surface. Spatial sound attenuation in the atmosphere, defined as "classic", as well as molecular absorption, according to the ISO/TC 43 data, when planning measures to combat noise pollution, is recommended to be taken into account (for temperature $+15{ }^{\circ} \mathrm{C}$ and relative humidity of 70 ), using the following indicators (Table 4).

Reduction of noise near the ground surface is affected by its character. It has been experimentally established that under real conditions there are observed deviations of the measured sound pressure levels from those calculated in accordance with formulas that take into account the free circulation of sound in the direction of decreasing and increasing the values obtained. Additional in relation to damping in the free space change in the level of noise (additional damping) is a consequence of interference and diffraction effects associated with the propagation of sound from a source located above the ground surface. Studies have shown that the additional attenuation de-
Table 4. Indicators for planning measures to combat noise pollution

\begin{tabular}{|l|c|c|c|c|c|c|c|}
\hline$f_{1}[\mathrm{~Hz}]$ & 63 & 125 & 250 & 500 & 1000 & 2000 & 4000 \\
\hline$\alpha[\mathrm{dB}(\mathrm{A}) / \mathrm{km}]$ & 0.2 & 0.3 & 0.7 & 1.6 & 4.0 & 9.7 & 27.6 \\
\hline
\end{tabular}

Notes: $f_{1}$ - oscillation frequency; $\alpha$ - sound level change factor.

pends on the frequency, the distance between the source and the receiver, their height above the ground surface, and the nature of ground surface relief.

As a result of the experimental studies, in the acoustic range maps were obtained of noise levels at the roadside area of localities by the methods of planning and building, where the curves of equal sound levels show a relative decrease in the level of the source - the first axis of vehicular traffic on the carriageway (Figure 1), as well as a nomogram developed for determining the level of noise pollution of the roadside area (Figure 2).

On the basis of a large number of field measurements, a graph of traffic flow acoustic emission was created for different categories of vehicular traffic (Figure 3). Using this graph, one can determine the value of sound level $L_{A \text { equiv }}$ (also called acoustic emission $E$ ) when driving a motorcar or a truck for 1 hour in the case of one of the foregoing types of motion and three types of longitudinal profiles. On the basis of the values indicated in the graph and concerning the motion of motorcars or trucks at a given speed under the conditions of one type of traffic flow described previously, one can determine the value of acoustic emission, depending on the road type.

Further, we will confine ourselves to considering the road sections with a uniform vehicular traffic. On the hor- 
izontal sections of such roads, motorcars develop speeds of $90 \ldots 130 \mathrm{~km} / \mathrm{h}$, and trucks - of $70 \ldots 100 \mathrm{~km} / \mathrm{h}$. These values are typical and allow professionals who deal with transport acoustics to determine the sound levels with sufficient accuracy.

For the indicated categories of vehicles, the average acoustic emission has the following values:

- passenger cars (average speed of $90 \ldots 130 \mathrm{~km} / \mathrm{h}$ or more) $E=38.5 \mathrm{~dB}(\mathrm{~A})$;

- commercial vehicles (average speed of $70 \ldots 100 \mathrm{~km} / \mathrm{h}$ or more) $E=45.0 \mathrm{~dB}(\mathrm{~A})$.

The foregoing values can be used to predict the levels of sound. Slopes of $20 \ldots 40 \%$ have little impact on the noise caused by the movement of cars or trucks. In this
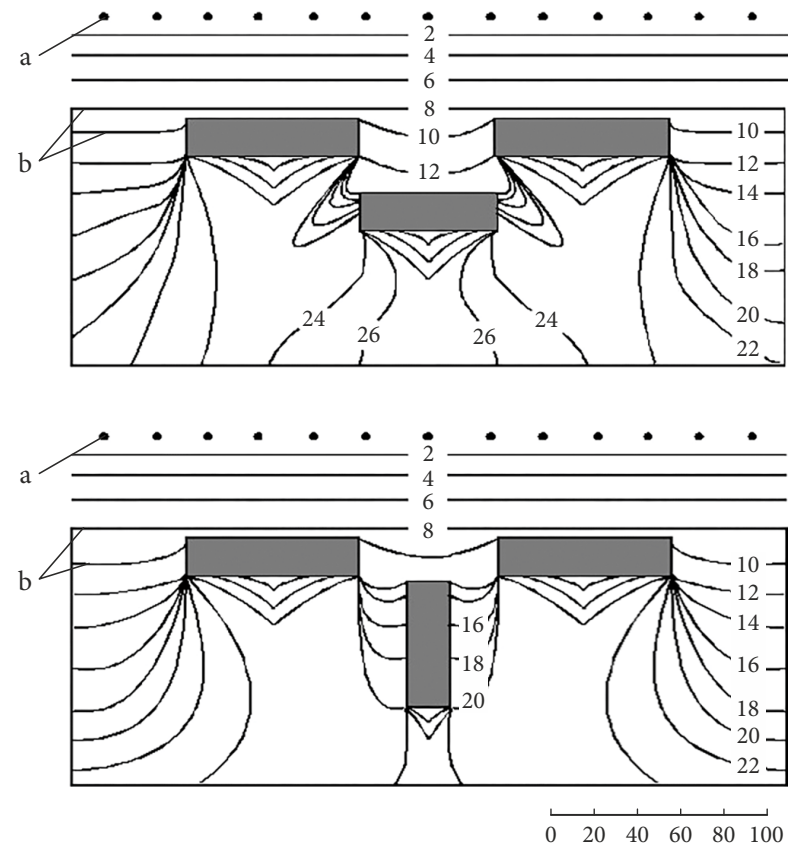

Figure 1. Maps of noise of roadside areas for different options of planning and development $[\mathrm{dB}(\mathrm{A})]$ : a - source of noise; $\mathrm{b}$ - curves of equal sound levels case, the average acoustic emission values are identical to those used in the prediction of the noise mode.

The graph in Figure 3 shows that the speed of passenger cars decreases as upgrade increases $(>40 \%$ ). If the range of base speeds on a flat road section is $90 \ldots 130$ $\mathrm{km} / \mathrm{h}$, the speed drops to $60 \ldots 105 \mathrm{~km} / \mathrm{h}$ in the presence of a steep rise. At downhill operation $(20 \ldots 40 \%)$, the speed increases, and the average acoustic emission in this case is $39.5 \mathrm{~dB}(\mathrm{~A})$. With a combination of downhill and uphill operation, the total energy value of acoustic emissions is very close to the value on the horizontal road section $38.5 \mathrm{~dB}(\mathrm{~A})$.

The same applies to road freight transport. At uphill operation $(>40 \%$ ), the speed is significantly reduced, and the value of the average acoustic emission $E_{\text {aver }}$ is close to $45.0 \mathrm{~dB}(\mathrm{~A})$. At downhill operation, the speed can increase, remain constant, or decrease (at braking), but the value of the average acoustic emission $E_{\text {aver }}$ remains close to $45.0 \mathrm{~dB}(\mathrm{~A})$.

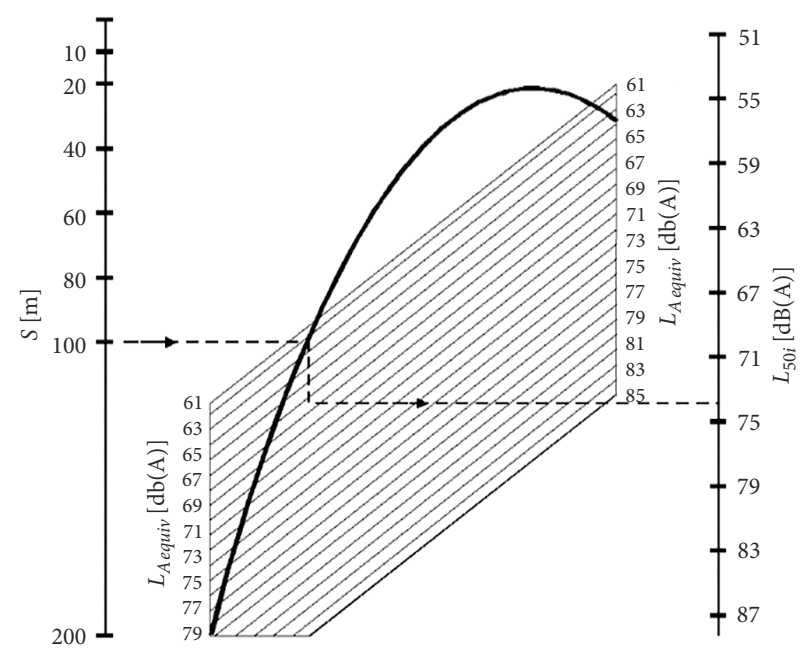

Figure 2. Nomogram for determining the level of noise pollution of the roadside area

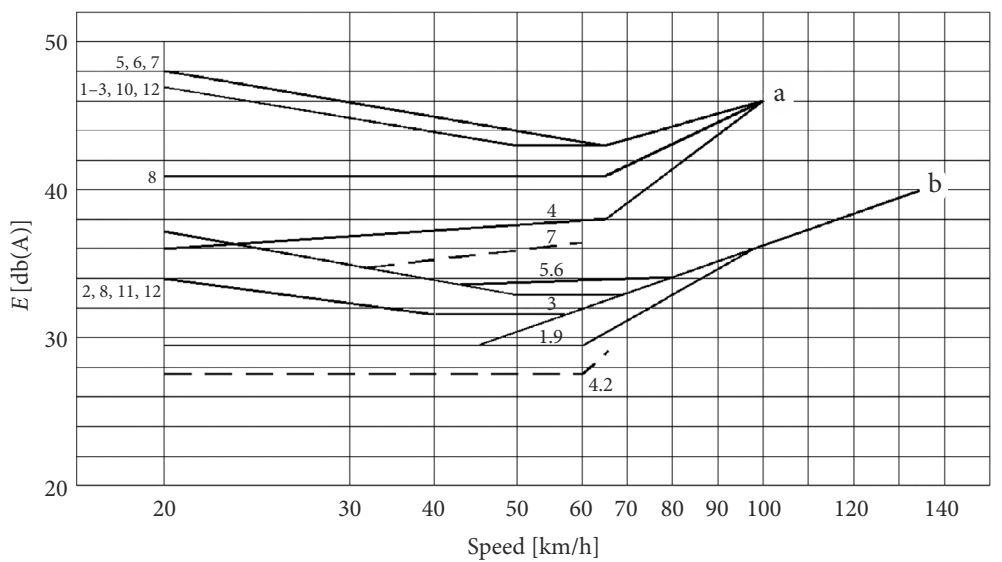

Figure 3. Acoustic emission $E[\mathrm{~dB}(\mathrm{~A})]$ as a function of the type, nature, and speed of the vehicle: $\mathrm{a}$ - truck, $\mathrm{b}$ - motorcar; character of movement: 1 - continuous sloping, 2 - pulsating with a slope, 3 - acceleration with a slope, 4 - deceleration with a slope, 5 - continuous with a rise, 6 - pulsating with a rise, 7 - acceleration with a rise, 8 - slowdown with a rise, 9 - continuous downhill operation, 10 - pulsating downhill operation, 11 - acceleration at downhill operation, 12 - deceleration at downhill operation 
On roads with heavy traffic on horizontal road sections, the speed of passenger cars is $70 \ldots 120 \mathrm{~km} / \mathrm{h}$ during the partial loading of the road. The speed of trucks on these roads is $65 \ldots 90 \mathrm{~km} / \mathrm{h}$. For these types of vehicles and speed, the data chart gives the average value of acoustic emissions: passenger cars $-35.5 \mathrm{~dB}(\mathrm{~A})$; trucks $44.0 \mathrm{~dB}(\mathrm{~A})$. These values can be used as a base on the initial curve of equal sound levels in predicting $L_{A \text { equiv }}$.

It should be noted that on road sections with a large rise the speed range is narrowed, and the average acoustic emission of passenger cars corresponds to approximately the value of emission in the absence of a slope $35.0 \mathrm{~dB}(\mathrm{~A})$. At downhill operation, on the contrary, the average speed can be increased by $10 \ldots 20 \mathrm{~km} / \mathrm{h}$ and cause the emission of sound equal to $36.5 \ldots 37.5 \mathrm{~dB}(\mathrm{~A})$. With bilateral traffic and the presence of a rise and slope, the level of average emission is $36.0 \ldots 36.5 \mathrm{~dB}(\mathrm{~A})$ (more than on a horizontal road section).

In trucks in the presence of a steep climb $(\sim 60 \%)$, the velocity decreases and causes a significant increase in the base level of noise emission, which is explained by an increase in the noise exposure time in the reference points and intensive operation of the engine. Acoustic emission in this case reaches $46.0 \ldots 47.5 \mathrm{~dB}(\mathrm{~A})$. At moderate slopes $(20 \ldots 40 \%)$, acoustic emission has an average value between the foregoing values and acoustic emission on a horizontal road section. During the downhill operation, the speed of trucks can be very different, and the average acoustic emission is similar to the one on a horizontal road section $-44.0 \mathrm{~dB}(\mathrm{~A})$. With two-way traffic, the two previously described situations are summed up, and the average acoustic emission $E_{\text {aver }}$ varies $44.0 \ldots 47.0 \mathrm{~dB}(\mathrm{~A})$ at low and high grades. In general, when driving on roads of the I and II categories, slopes have a moderate impact on the acoustic situation; in the case of steep slopes ( $40 \%$ or more), an increase in acoustic emission by $1.0 \ldots 2.0 \mathrm{~dB}(\mathrm{~A})$ is produced compared with a horizontal road section.

The foregoing values of acoustic emission correspond to the sound level $L_{\text {A equiv }}$ (during $1 \mathrm{~h}$ ), expressed in $\mathrm{dB}(\mathrm{A})$, on the initial curve of equal sound levels when driving one car per hour (car or truck) on the road, located on the ground level and apparently (perceived) at an angle of $180^{\circ}$. The meaning of acoustic emission when driving a vehicle corresponds to the sound level $L_{\text {A equiv }}$ (during $1 \mathrm{~h}$ ) at a point located $30 \mathrm{~m}$ from the edge of the roadway and at a height of $10 \mathrm{~m}$, in the absence of obstacles and under the condition that the surface has a high reflectivity. To get the real value of the sound level at a given reference point, the correction index that takes into account the impact of acoustic emission in space should be added or subtracted.

The level of emissions from each vehicle in the traffic flow can be determined with a high accuracy, depending on the speed and nature of the traffic flow and movement of cars and trucks. To determine the level of emission produced by a stream of vehicles, it is sufficient to add the noise levels caused by different types of vehicles. But in the absence of data required for this calculation (data concerning the speed of each transport flow), especially with- in the prediction of sound levels (when only the intensity of movement is determined), the level of traffic flow is calculated on the basis of average levels of acoustic emissions. At the same time, on the road there is expected vehicular traffic characteristic of one of the four types previously described: continuous smooth, continuous pulsing, pulsating acceleration, or deceleration. To get the sound level on the initial curve of equal sound levels at a given vehicular traffic intensity per hour, one should add $10 \cdot \lg N$ to the value of acoustic emission of an average vehicle.

Roads laid in a small recess are referred to (depths of less than $2 \mathrm{~m}$ ) as roads with the ability to absorb sound. For roads with such a transverse profile, two graphs are used: for a short distance, one of the three graphs of acoustic emission under conditions of a sound reflecting surface; for distances of over 30 meters, a graph showing the sound absorption due to the impact of the ground surface.

The amount of sound reduction at its propagation in space is equal to the sum of sound attenuation performance, defined by these two graphs at a distance corresponding to the position of the reference point. The graph shows the additional attenuation of sound near the absorbing surface with respect to the performance of acoustic emission near the surface that reflects sound.

The paper examines the overall impact of road performance indicators and geometric parameters on acoustic pollution of residential areas of roadside lanes. This analysis is novelty of this paper. The obtained data will be used by the impulse method for solving wave acoustic radiation equations due to the traffic flow. The solution of wave acoustic radiation equations due to the traffic flow taking into account the overall impact of road performance indicators and geometric parameters, allows one to determine:

- noise level when vehicle is moving in a free trajectory;

- level of acoustic pollution at a certain distance from the road's axial line;

- level of acoustic pollution in the presence of a predetermined mobile coordinate system associated with a sound source (traffic flow).

\section{Conclusions}

1) Studies have shown that the additional attenuation depends on the frequency, the distance between the source and the receiver, their height above the ground surface, and the nature of ground surface relief;

2) Roads laid in a small recess are referred to (depths of less than $2 \mathrm{~m}$ ) as roads with the ability to absorb sound. For roads with such a transverse profile, two graphs are used: for a short distance, one of the three graphs of acoustic emission under conditions of a sound reflecting surface; for distances of over $30 \mathrm{~m}$, a graph showing the sound absorption due to the impact of the ground surface; 
3) Slopes of $20 \ldots 40 \%$ have little impact on the noise caused by the movement of passenger cars and trucks. In this case, the average acoustic emissions are identical to those used in the prediction of noise mode. In general, when driving on roads of the I and II categories, slopes have a moderate impact on the acoustic situation; in the case of steep slopes ( $40 \%$ or more), an increase in acoustic emission by $1.0 \ldots 2.0 \mathrm{~dB}(\mathrm{~A})$ is produced compared with a horizontal road section;

4) At downhill operation $(20 \ldots 40 \%)$, the speed increases, and the average acoustic emission in this case is $39.5 \mathrm{~dB}(\mathrm{~A})$. With a combination of downhill and uphill operation, the total energy value of acoustic emissions is very close to the value on the horizontal road section $-38.5 \mathrm{~dB}(\mathrm{~A})$;

5) On roads with heavy traffic on horizontal road sections, the speed of passenger cars is $70 \ldots 120 \mathrm{~km} / \mathrm{h}$ during the partial loading of the road. The speed of trucks on these roads is $65 \ldots 90 \mathrm{~km} / \mathrm{h}$. For these types of vehicles and speed, the data chart gives the average value of acoustic emissions: passenger cars $-35.5 \mathrm{~dB}(\mathrm{~A})$; trucks $-44.0 \mathrm{~dB}(\mathrm{~A})$. These values can be used as a base on the initial curve of equal sound levels in predicting $L_{\text {A equiv; }}$;

6) On the basis of field measurements, a graph of traffic flow acoustic emission was created for different categories of vehicular traffic. Using this graph, one can determine the value of sound level (also called acoustic emission) when driving a motorcar or a truck for $1 \mathrm{~h}$ in the case of one of the types of motion and three types of longitudinal profiles. On the basis of the values indicated in the graph and concerning the motion of motorcars or trucks at a given speed under the conditions of one type of traffic flow, one can determine the value of acoustic emission, depending on the road type;

7) The paper examines the overall impact of road performance indicators and geometric parameters on acoustic pollution of residential areas of roadside lanes. The obtained data will be used by the impulse method for solving wave acoustic radiation equations due to the traffic flow.

\section{References}

Bikuviené, I.; Juodkiené, V. 2017. Simulation and analysis of car noise pollution in the territory of Kaunas university of applied sciences, in Sinteza 2017: International Scientific Conference on Information Technology and Data Related Research: Book of Proceedings, 21 April 2017, Belgrade, Serbia, 291-296. https://doi.org/10.15308/Sinteza-2017-291-296

Den Boer, L. C.; Schroten, A. 2007. Traffic Noise Reduction in Europe: Health Effects, Social Costs and Technical and Policy Options to Reduce Road and Rail Traffic Noise. CE Delft, The Netherlands. 70 p. Available from Internet: https://www.cedelft.eu/publicatie/traffic_noise_reduction_in_europe/821
EEA. 2014. Noise in Europe 2014. European Environment Agency (EEA) Report No 10/2014. Copenhagen, Denmark. 68 p. Available from Internet: https://doi.org/10.2800/763331

GOST 31330.1:2006. Shum. Ocenka vliyaniya dorozhnogo pokrytiya na transportnyj shum. Chast' 1. Statisticheskij metod [Noise. Measurement of the influence of road surfaces on traffic noise. Part 1. Statistical method]. (in Russian).

Ho, K.-Y.; Hung, W.-T.; Ng, C.-F.; Lam, Y.-K.; Leung, R.; Kam, E. 2013. The effects of road surface and tyre deterioration on tyre/road noise emission, Applied Acoustics 74(7): 921-925. https://doi.org/10.1016/j.apacoust.2013.01.010

IEC 60942:2017. Electroacoustics - Sound Calibrators.

Ilgakojis, P.; Jotautiene, E.; Merkevicius, S.; Bazaras, J. 2005. An investigation of infrasonic in traffic flow noise, WIT Transactions on The Built Environment 77: 511-520.

ISO 11819-1:1997. Acoustics - Measurement of the Influence of Road Surfaces on Traffic Noise - Part 1: Statistical Pass-By Method.

ISO 11819-2:2017. Acoustics - Measurement of the Influence of Road Surfaces on Traffic Noise - Part 2: The Close-Proximity Method.

ISO/TC 43. Acoustics.

Masino, J.; Pinay, J.; Reischl, M.; Gauterin, F. 2017. Road surface prediction from acoustical measurements in the tire cavity using support vector machine, Applied Acoustics 125: 41-48. https://doi.org/10.1016/j.apacoust.2017.03.018

Miškinytè, A.; Dėdelè, A. 2014. Evaluation and analysis of traffic noise level in Kaunas city, in 9th International Conference on Environmental Engineering: Selected Papers, 22-23 May 2014, Vilnius, Lithuania, 1-6.

https://doi.org/10.3846/enviro.2014.036

Mohamed, Z.; Wang, X. 2016. A deterministic and statistical energy analysis of tyre cavity resonance noise, Mechanical Systems and Signal Processing 70-71: 947-957.

https://doi.org/10.1016/j.ymssp.2015.09.012

Moon, H. R.; Kang, W. P.; Lim, Y. J. 2013. Development and basic experiment of active noise control system for reduction of road noise, International Journal of Highway Engineering 15(6): 41-47. https://doi.org/10.7855/IJHE.2013.15.6.041 (in Korean).

Morgan, P. (Ed.). 2006. Guidance Manual for the Implementation of Low-Noise Road Surfaces. Forum of European National Highway Research Laboratories (FEHRL) Report No 2006/2. Brussels, Belgium. 332 p.

Nucara, A.; Pietrafesa, M.; Scaccianoce, G.; Staltari, G. 2001. A comparison between analytical models and artificial neural networks in the evaluation of traffic noise levels, in Proceedings of the 17th International Congress on Acoustics, 2-7 September 2001, Rome, Italy, 208-209.

Parnell, J.; Samuels, S. 2006. A comparison of tyre/road noise generated on NSW pavements to international studies, in Proceedings of Acoustics 2006: Noise of Progress, 20-22 November 2006, Christchurch, New Zealand, 369-375.

Samuels, S.; Parnell, J. 2001. Some recent Australian developments in the reduction of road pavement noise, in Australian Acoustical Society Annual Conference: Acoustics 2001: Noise and Vibration Policy - the Way Forward?, 21-23 November 2001, Canberra, Australia, A3.2/1-A3.2/12.

Sandberg, U.; Ejsmont, J. A. 2002. Tyre/Road Noise Reference Book. Informex. 640 p. 
Sandberg, U.; Glaeser, K.-P. 2008. Effect of tyre wear on noise emission and rolling resistance, in 37th International Congress and Exhibition on Noise Control Engineering 2008 (Inter-Noise 2008), 26-29 October 2008, Shanghai, China, 5241-5260.

Smolnikovas, M.; Viselga, G.; Viselgaitè, G.; Jasinskas, A. 2015. Dyzelinių variklių su įvairiomis ịpurškimo sistemomis išmetamųjų dujų tyrimas [Diesel engine with different kind of injection systems exhaust gas analysis], Mokslas - Lietuvos ateitis [Science - Future of Lithuania] 7(5): 594-600. https://doi.org/10.3846/mla.2015.841 (in Lithuanian).

Tanaka, Y.; Horikawa, S.; Murata, S. 2016. An evaluation method for measuring SPL and mode shape of tire cavity resonance by using multi-microphone system, Applied Acoustics 105: 171-178. https://doi.org/10.1016/j.apacoust.2015.12.009

Ugnenko, E. B. 2008. Metodologiya proektirovaniya rekonstrukcii avtomobil'nyh dorog s uchetom jekologicheskih pokazatelej: Monografiya. Har'kov: HNADU. 184 s. (in Russian).

Ugnenko, E.; Perova, E.; Voronova, Y.; Viselga, G. 2017. Improvement of the mathematical model for determining the length of the runway at the stage of aircraft landing, Procedia Engineering 187: 733-741.

https://doi.org/10.1016/j.proeng.2017.04.448

WHO. 2018. Noise: Data and Statistics. World Health Organization (WHO), Regional Office for Europe, Copenhagen, Denmark. Available from Internet: http://www.euro.who.int/ en/health-topics/environment-and-health/noise/data-andstatistics 